\title{
Synthesis of hybrid nanofluid with two-step method
}

\author{
Wayan Nata Septiadi ${ }^{1,2,}$, Ida Ayu Nyoman Titin Trisnadewi ${ }^{2,3}$, Nandy Putra ${ }^{4}$ and Iwan Setyawan ${ }^{5}$ \\ ${ }^{1}$ Department of Mechanical Engineering Udayana University, Kampus Bukit Jimbaran Badung-Bali, Indonesia \\ ${ }^{2}$ Heat Transfer Laboratory Department of Mechanical Engineering Udayana University \\ ${ }^{3}$ Bachelor Programme Student of Department of Mechanical Engineering, Udayana University \\ ${ }^{4}$ Department of Mechanical Engineering University of Indonesia, Kampus Baru UI-Depok \\ ${ }^{5}$ Department of Mechanical Engineering University of Gunadarma, Depok-Indonesia
}

\begin{abstract}
Nanofluid is a liquid fluid mixture with a nanometer-sized solid particle potentially applied as a heat transfer fluid because it is capable of producing a thermal conductivity better than a base fluid. However, nanofluids have a weakness that is a high level of agglomeration as the resulting conductivity increases. Therefore, in this study, the synthesis of two nanoparticles into the base fluid called hybrid nanofluids. This study aims to determine the effect of nanoparticle composition on the highest thermal conductivity value with the lowest agglomeration value. This research was conducted by dispersing $\mathrm{Al}_{2} \mathrm{O}_{3}-\mathrm{TiO}_{2}$ nanoparticles in water with volume fraction of $0.1 \%, 0.3 \%, 0.5 \%, 0.7 \%$ in the composition of $\mathrm{Al}_{2} \mathrm{O}_{3}-\mathrm{TiO}_{2}$ ratio of $75 \%: 25 \%, 50 \%: 50 \%, 25 \%: 75 \%$. The synthesis was performed with a magnetic stirrer for 30 minutes. The tests were carried out in three types: thermal conductivity testing with KD2, visual agglomeration observation and absorbance measurements using UV-Vis, wettability testing with $\mathrm{HSVC}$ tools and Image applications. The test results showed that the ratio composition ratio of $75 \% \mathrm{Al}_{2} \mathrm{O}_{3}-25 \% \quad \mathrm{TiO}_{2}$ with a volume fraction of $0.7 \%$ resulted in an increase in optimum thermal conductivity with the best wettability and the longest agglomeration level.
\end{abstract}

\section{Introduction}

Nanofluid was first coined by Choi in 1995 from the Argonne National Laboratory, the United States to describe a stable colloid mixture or suspension between solid particles that have a diameter in nanometers $\left(10^{-9}\right.$ m) into a fluid base fluid.[1,2,3] Nano Technology itself is the manufacture and use of materials or equipment in very small sizes. This material is in the realm of $1-100$ $\mathrm{nm}$ where one $\mathrm{nm}$ is equal to one-billionth of a meter $(0.000000001 \mathrm{~m})$. Scientists refer to the size in the 1 $100 \mathrm{~nm}$ realm as the nanoscale and the material in this realm is referred to as nanoparticles or nanomaterials[1,4]. Nanoparticles can be chemically stable metals, metal oxides, oxide ceramics, metal carbides, metal nitrides and carbon. The basic fluids used can be water, organic liquids, biocides, oils and lubricants[5].

Nanofluid is a liquid which is said to be potentially applicable to industries such as microelectronics, transportation and manufacturing[6]. Theoretically nanofluid has a better thermal conductivity than its basic fluid, besides that brown motion effects will occur on nanoparticles which causes nanoparticles to float on the base fluid so as to minimize the occurrence of agglomeration in nanofluids. If applied, the possibility of clogging in the canal is very small, then because of the small particles, the abrasion between the nanofluid and the small duct wall occurs[7]. The development of nanofluid and its application can be said to be very rapid, this can be seen from the number of published articles and scientific writings. Some examples of research are Nandy Putra et.al [8] who conducted a study of the effects of nanofluid concentration on the performance of heat pipes [9] regarding sedimentation in nanofluids during natural convection experiments, Khaleduzzamana, et al. [10] about the stability of $\mathrm{Al}_{2} \mathrm{O}_{3}$ nanofluid water for electronic cooling systems and much more.

Along with the development of nanofluid-related research technology, it is continuously improved to obtain the best properties. It is known that single nanofluid does not have all the characteristics that are beneficial for certain applications. In a single nanofluid, there are problems, where the thermal conductivity is high but easily agglomerated and vice versa [11]. Agglomeration has a negative impact on nanofluid stability, accelerates the deposition of nanoparticles due to gravity and causes a decrease in the ability of nanofluids to conduct heat[12]. In addition to thermal conductivity and agglomeration, the ability of nanofluid in conducting heat is also influenced by wettability. Because of these problems, researchers began developing and conducting research on hybrid nanofluid. Hybrid nanofluids are new nanotechnology fluids synthesized by decomposing two different nanoparticles

Corresponding author: wayan.nata $@$ gmail.com 
into conventional heat transfer fluids[13,14]. The purpose of incorporating hybrid nanoparticles in a base fluid is to improve the characteristics of the basic fluid heat transfer through a combination of thermo-physical properties of the nanomaterial[5]. Devendiran and Amirtham[15] state that synthetic hybrid nanoparticles provide improvements in the physical-chemical properties not obtained in nanofluids using single nanomaterials.

Several studies that have been carried out on hybrid nanofluids are, Moh. Hemmat Esfe1, et.al [16] concerning the study of water-based nanostructural thermal conductivity of water with hybrid suspensions of $\mathrm{CNT} / \mathrm{Al}_{2} \mathrm{O}_{3}$ nanoparticles, Suleiman Akilu, et al., [17] about experimental measurements of thermal conductivity and viscosity of hybrid nanofluid-based ethylene glycol with $\mathrm{TiO}_{2}-\mathrm{CuO} / \mathrm{C}$ inclusions, Alireza Azadi Charab, et al.,[18] concerning the thermal conductivity of $\mathrm{Al}_{2} \mathrm{O}_{3}-\mathrm{TiO}_{2}$-water with model development and validation experimental and there are many more researches on his research. This study clearly shows that hybrid nanofluids produce a higher increase in heat transfer than a single nanofluid.

To obtain a desired nanofluid hybrid liquid, a nanofluid hybrid process is not as simple as imagined. Some criteria must be met so that the resulting fluid can be used, among others, such as solid-liquid suspension stability, solid-liquid suspension resistance, no occurrence of suspended nanoparticles, no chemical changes in materials and others. Broadly speaking, the manufacture of nanofluidics is divided into 2 techniques, namely one-step technique, and a two-step technique. The one-step method combines the synthesis of nanoparticles and their distribution into the base fluid in one step [15]. The two-step method is commonly used in fluid-related research. In this method, the first nanoparticles are produced and then dispersed into basic liquids. Commercial nanoparticles or nanopowder that can be used can be bought easily on the market [19].

In this study, the manufacture of hybrid nanofluid using $\mathrm{Al}_{2} \mathrm{O}_{3}$ nanoparticles and $\mathrm{TiO}_{2}$ with the basic fluid is water. The technique used in this study is a two-step technique by synthesizing $\mathrm{Al}_{2} \mathrm{O}_{3}$ and $\mathrm{TiO}_{2}$ commercial nanoparticles into the base fluid using an ultrasound processor. Hybrid nanofluid that has been synthesized will be tested for the resulting conductivity values and agglomeration levels to determine the optimization of the use of the two-step synthesis method.

\section{Methodology}

\subsection{Two-step method hybrid nanofluid synthesis}

Hybrid nanofluid is made by mixing $\mathrm{Al}_{2} \mathrm{O}_{3}$ and $\mathrm{TiO}_{2}$ nanoparticles into a basic fluid in the form of distilled water. In these hybrid nanofluid several concentrations were examined, namely $0.1 \%, 0.3 \%, 0.5 \%, 0.7 \%$ with the composition of the fraction of the comparison volume between $\mathrm{Al}_{2} \mathrm{O}_{3}-\mathrm{TiO}_{2}$ was $25 \% \mathrm{Al}_{2} \mathrm{O}_{3}: 75 \% \mathrm{TiO}_{2}$, $50 \% \quad \mathrm{Al}_{2} \mathrm{O}_{3}: 50 \% \quad \mathrm{TiO}_{2}$ and $75 \% \mathrm{Al}_{2} \mathrm{O}_{3}: 25 \% \mathrm{TiO}_{2}$. Nanoparticle volume measurements were carried out by means of nanoparticle mass multiplication with density, where $\mathrm{Al}_{2} \mathrm{O}_{3}$ nanoparticles had a density of $0.18 \mathrm{~g} / \mathrm{ml}$ and $\mathrm{TiO}_{2}$ of $0.24 \mathrm{~g} / \mathrm{ml}$.

To obtain a desired nanofluid hybrid liquid, a nanofluid hybrid process is not as simple as imagined. Some criteria must be met so that the resulting fluid can be used, among others, such as solid-liquid suspension stability, solid-liquid suspension resistance, no occurrence of suspended nanoparticles, no chemical changes in materials and others.

In the two-step method, nanoparticles are produced separately and suspended in a fluid base fluid. In this method, hybrid nanopowder is first produced through chemical, physical or mechanical processes such as grinding, gel process or vapor phase method. Then the prepared hybrid nanopowder is then dispersed into the base liquid using high shear mixing using an ultrasonic processor. Making a nanofluid hybrid with a two-step method can be economically produced on a large scale. However, the main complexity is agglomeration that cannot be avoided based on cohesive strength and Vander Waal among independent nanoparticles. This agglomeration can be sufficiently suppressed by using surfactants or dispersants that are appropriate at critical micelle concentrations. Agglomeration can also be minimized by using appropriate dispersing devices such as ultrasonic baths, magnetic stirrers, high-pressure homogenizers and ultrasonic jammers. Hybrid nano liquids from different nanoparticles and basic fluids found prepared by one of the two methods above depending on their suitability $[11,20,21]$.

Based on this, this study uses a two-step method by synthesizing two nanoparticles, namely $\mathrm{Al}_{2} \mathrm{O}_{3}$ and $\mathrm{TiO}_{2}$ into the fluid which is used is distilled water. The particles used are commercial nanoparticles from Nano Degussa with a size of $20 \mathrm{~nm}$. Synthesized Hybrid Nanofluid using Ultrasonic Processor for 30 minutes. The sinteshys nanofluid hybrid scheme can be seen in Figure 1.

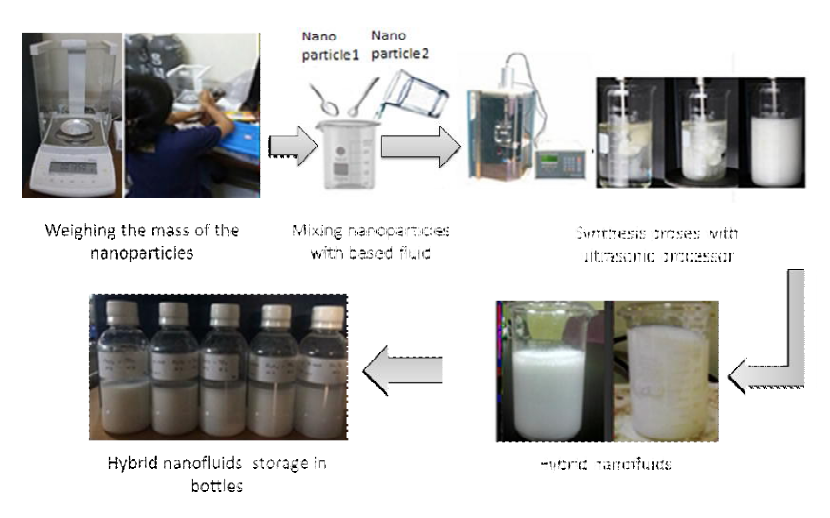

Fig. 1. The process of making $\mathrm{Al}_{2} \mathrm{O}_{3}-\mathrm{TiO}_{2}$-water hybrid nanofluid. 


\subsection{Hybrid Nanofluid Testing}

\subsubsection{Thermal Conductivity Testing}

KD2 Pro thermal properties analysis has been used to measure hybrid nanofluid thermal conductivity. This instrument is a commercial device, which is usually used to determine the thermal conformation of a liquid (nanofluid) in the range $0.02-2 \mathrm{~W}_{-} \mathrm{LC}^{-1}$ with a $\mathrm{KS} 1$ sensor using a transient hot-wire method. The KS1 sensor is made of stainless steel and has an accuracy of $5 \%$ and a length of $60 \mathrm{~mm}$ and a diameter of $1.27 \mathrm{~mm}$, which is placed in a nanofluid. The THW method measures the temperature/time response of the wire to a sudden electric pulse. Measuring the thermal conductivity of the prepared sample, the sensor is inserted into the sample vertically to minimize free convection. Any deviation from the vertical position will bring errors into the data reported $[16,22]$.

The measurement lasts for 90 seconds which consists of the initial process by heating and cooling the sensor 30 seconds each which then the sensor will calculate the heat balance between the heating and cooling processes.

Measurements were made on the test tube with a fluid amount of $\pm 20 \mathrm{ml}$, where temperature conditioning measurements were carried out using Circulating Thermostatic Bath (CTB)[14].

\subsubsection{Agglomeration observation}

Nanofluid agglomeration occurs due to clumping between particles due to van der Waals force and weakening of brown motion in a nanofluid. Agglomeration causes a decrease in the level of homogeneity in nanofluid so the particles will tend to settle at the bottom and cause nanofluid to appear clear at the top. Therefore, the observation of agglomeration can be done visually.

In this study also observed the agglomeration using UV-Vis by measuring the absorbance of nanofluid. Absorption of absorbance data is done because the ability to observe the sediment of each person is different, $\mathrm{Al} 2 \mathrm{O} 3$ and $\mathrm{TiO} 2$ nanofluids are white and cloudy so they cannot clearly see the sediment formed. Taking absorbance data using UV-Vis Double Beam Shimadzu/UV-1800, UV Probe software is used to display the results of absorbance measurements. the wavelength used in the test is 200-680 $\mathrm{nm}$. the absorbance data was taken three times, one day after synthesis, 8 days after synthesis and 15 days after synthesis.

\subsubsection{Wettability Testing}

Nanofluid wettability observed using HSCV (high-speed camera video) is carried out by doing a nanofluid penetration on a flat plane and high-resolution cameras will record the behavior of the fluid on a flat plane surface. In this test, the flat field used is the powder wick sintered surface and Figure $3 a$ is a wettability testing scheme. The images obtained from HSVC then measured the contact angle using ImageJ software. The measurement method is done by measuring the angle between the tangent lines of the fluid droplets and the flat surface. The method of measurement can be seen in Figure $2 b$.

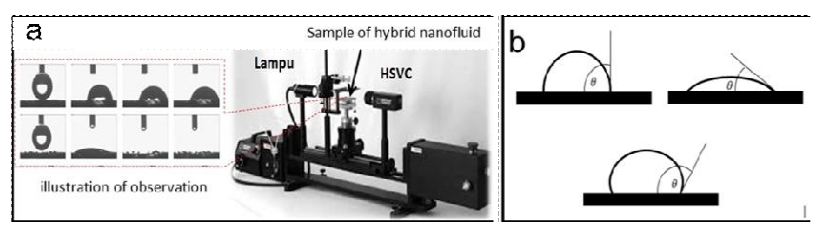

Fig. 2. (a) Wettability testing scheme, (b) Measurement of nanofluid contact angles on a flat surface

\section{Result and Discussion}

\subsection{Thermal Conductivity Test Results}

KD2 The graph of thermal conductivity of each ratio $\left(75 \% \mathrm{Al}_{2} \mathrm{O}_{3}: 25 \% \mathrm{TiO}_{2}, 50 \% \mathrm{Al}_{2} \mathrm{O}_{3}: 50 \% \mathrm{TiO}_{2}, 25 \%\right.$ $\mathrm{Al}_{2} \mathrm{O}_{3}: 75 \% \mathrm{TiO}_{2}$ ) shows an increase in the value of thermal conductivity produced as the size of the nanofluid hybrid volume fraction increases. in high or low concentrations. In addition, it can also be seen in the graph that the value of thermal conductivity produced by hybrid nanofluid is greater than the value of the thermal conductivity of the basic fluid, namely water. So that it can be seen that the manufacture of nanofluid hybrids using $\mathrm{Al}_{2} \mathrm{O}_{3}$ and $\mathrm{TiO}_{2}$ nanoparticles can produce an increase in thermal conductivity better than the base fluid.

It can also be seen that the ratio that produces the greatest thermal conductivity value is at a ratio of $75 \%$ $\mathrm{Al}_{2} \mathrm{O}_{3}: 25 \% \mathrm{TiO}_{2}$. This is reasonable because the thermal conductivity of $\mathrm{Al}_{2} \mathrm{O}_{3}$ nanoparticles is indeed higher than that of $\mathrm{TiO}_{2}$ thermal conductivity. So that the composition of the percentage of $\mathrm{Al}_{2} \mathrm{O}_{3}$ will produce a greater thermal conductivity value as well. This result is also supported by research conducted by Septiadi et al.,[14] in his research related to the characterization of $\mathrm{H} 2 \mathrm{O}$ base fluid based thermal conductivity using three nanoparticles namely $\mathrm{CuO}, \mathrm{Al}_{2} \mathrm{O}_{3}$ and $\mathrm{TiO}_{2}$. The results of the research showed that the thermal conductivity value of $\mathrm{Al}_{2} \mathrm{O}_{3}$-Water nanofluid was greater than the value of thermal conductivity produced by a $\mathrm{TiO}_{2}$-water nanofluid.

Based on this graph, it can also be seen that the point that has the highest increase in thermal conductivity is in the volume fraction of $0.7 \%$ with an increase in water percentage of $32.50 \%$. Then the calculation of the composition of the nanoparticles was carried out to find out the volume fraction which resulted in a significant increase in the mass of nanoparticles used. It aims to produce a more efficient nanofluid hybrid which enhances the best thermal conductivity with the use of appropriate nanoparticles and can produce hybrid nanofluid thermal conductivity which significantly 
increases the addition of nanoparticles used. The following are the results of the calculation of the use of nanoparticle composition at a volume fraction of 0.7 .

Referring to the table above it can be seen that the volume fraction of $0.7 \%$ with an increase in composition 6 times can increase thermal conductivity by $20 \%$ and $32.5 \%$. Therefore, it can be obtained that the optimal conductivity value of this test is at a ratio of $75 \%: 25 \%$ with a volume fraction of $0.7 \%$. It is seen that the increase in thermal conductivity is significant and with the minimum use of nanoparticles.

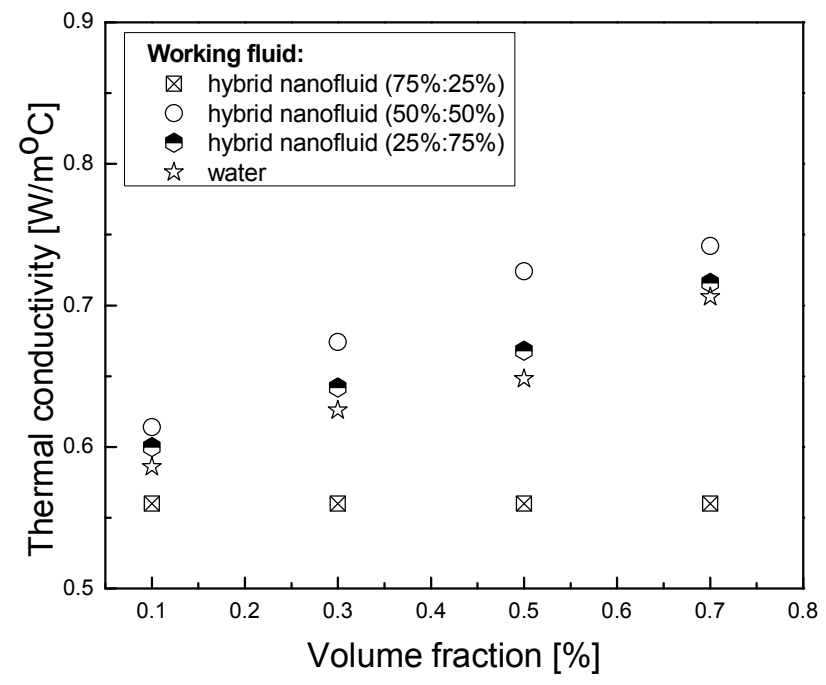

Fig. 3. (a) A comparative graph of three nanoparticle ratios

\subsection{Visually Observing Nanofluid Agglomeration}

In this study, single nanofluid agglomeration and hybrid nanofluid were observed visually while the agglomeration observation by measuring the absorbance using UV-Vis was only done on hybrid nanofluid alone. This is because single nanofluid is only used as comparative data to determine the ability of hybrid nanofluids in inhibiting agglomeration. The single hybrid nanofluid and nanofluid that have been synthesized are stored and observed agglomeration visually by looking at the sediment that occurs in the nanofluid, the time it takes for the nanoparticles to settle as a whole so that the nanofluid becomes clear can be seen in Figure 4.a.

Based on the picture above, it can be seen that the higher the volume fraction of the nanoparticles in the nanofluid, the longer the agglomeration. $\mathrm{Al}_{2} \mathrm{O}_{3}$ single nanofluid at $0.7 \%$ volume fraction is agglomerated for 25 days and the fastest agglomerated is nanofluids $\mathrm{TiO}_{2}$ at $0.1 \%$ volume fraction for 4 days of storage. In the same volume fraction, $\mathrm{Al}_{2} \mathrm{O}_{3}$ nanofluid is agglomerated longer than $\mathrm{TiO}_{2}$ nanofluid and hybrid nanofluid containing more $\mathrm{Al}_{2} \mathrm{O}_{3}$ particles also agglomerated longer. This shows that the stability of $\mathrm{Al}_{2} \mathrm{O}_{3}$ particles is better than $\mathrm{TiO}_{2}$ particles. Based on visual observations of single nanofluid homogeneity and hybrid nanofluidics decreases with increasing storage time, this is caused by the brown motion effect on the weakened nanoparticles due to clumping between nanoparticles because the clumping of nanoparticles will be sedimentation in the lower portion and the nanofluid becomes clear. Changes in nanofluid homogeneity are shown in Figure 4.b

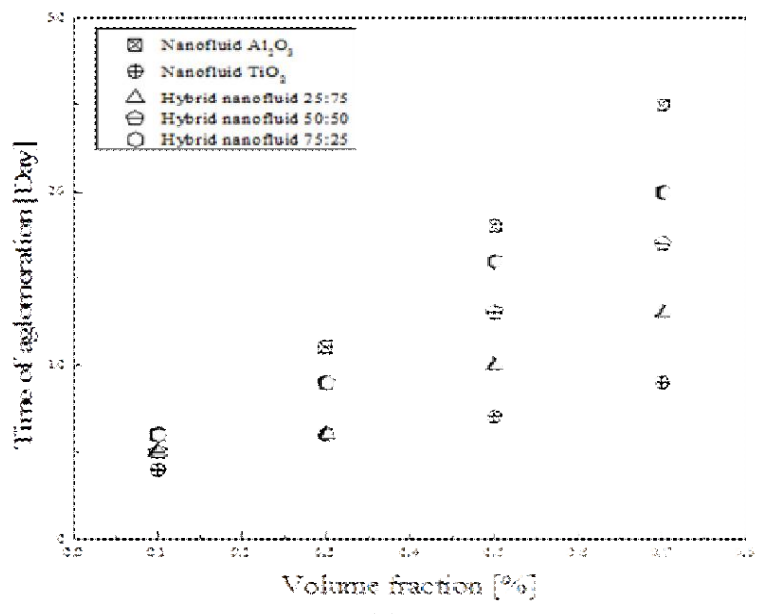

(a)

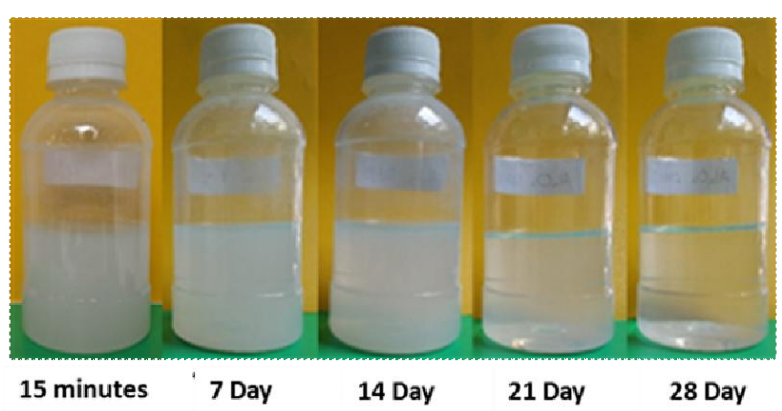

(b)

Fig. 4. (a) Single nanofluid agglomeration time graph and nanofluid hybrid with variations in volume fraction and composition of $\mathrm{Al}_{2} \mathrm{O}_{3}: \mathrm{TiO}_{2}$ nanoparticles in hybrid nanofluid, (b) Change of $\mathrm{Al}_{2} \mathrm{O}_{3}$ nanofluid homogeneity in volume fraction of $0.7 \%$

\subsection{Agglomeration Observation Using UV-Vis}

This study also observed agglomeration using UV-Vis by measuring the absorbance of hybrid nanofluids. Because most of the absorbance peaks of hybrid nanofluid test results are 4 , where the maximum limit of measurement from UV-Vis Double Beam Shimadzu/UV-1800 is 4 it allows overscale in its measurement so that if the absorbance value is more than 4 then UV-Vis will display at the maximum limit. Therefore, to compare the absorbance of each hybrid nanofluid is done by calculating the average absorbance of the combustion length of $200-680 \mathrm{~nm}$. Figure 5 is one of the absorbance measurements and table 3 is the average data of absorbance measurements.

From table 4 , it can be seen that the absorbance of all hybrid nanofluids decreases with increasing storage time, this indicates a decreased nanofluid hybrid homogenus. And with increasing nanofluid hybrid absorbance volume fraction increases. 


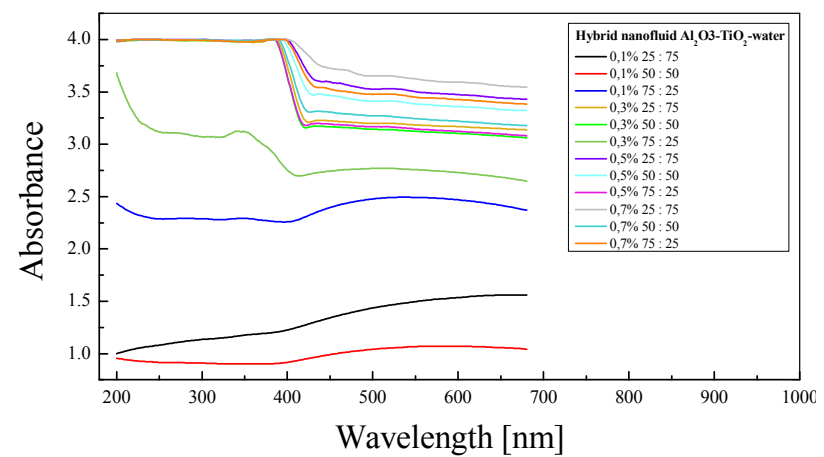

Fig. 5. Low concentration hybrid nanofluid absorbance 8 days after synthesis

Based on the results of absorbance measurements, in the same volume fraction, most of the nanofluid hybrids containing $75 \%$ of $\mathrm{Al}_{2} \mathrm{O}_{3}$ particles have a higher absorbance value. This shows that nanofluid containing more $\mathrm{Al}_{2} \mathrm{O}_{3}$ particles has better stability. The visual agglomeration observation also showed that the same nanofluid hybrid volume fraction containing more $\mathrm{Al}_{2} \mathrm{O}_{3}$ particles had better stability and there was a single nanofluid, $\mathrm{TiO}_{2}$ nanofluid was agglomerated faster than $\mathrm{Al}_{2} \mathrm{O}_{3}$ nanofluid.

Nanofluid hybrid agglomeration which contains more $\mathrm{Al}_{2} \mathrm{O}_{3}$ particles is slower because the browning effect lasts longer in particles and $\mathrm{Al}_{2} \mathrm{O}_{3}$ has a smaller density than $\mathrm{TiO}_{2}$. The slower agglomeration time occurs in the higher volume fraction because in the higher fraction there is a greater frictional force between the nanoparticles so that the nanoparticles will float in the basic fluid which causes the formation of sediment for a long time. This is in accordance with what is stated Geankoplis, [23] that the smaller the density will cause the buoyant force to increase and the greater the concentration of the frictional force experienced by the larger particles.

Table 1. Hybrid nanofluid absorbance averages at wavelengths of 200-680 nm

\begin{tabular}{|c|c|c|c|c|c|c|c|c|c|}
\hline \multirow{2}{*}{$\begin{array}{c}\text { Volume } \\
\text { fraction } \\
(\%)\end{array}$} & \multicolumn{3}{|c|}{$25 \% \mathrm{Al}_{2} \mathrm{O}_{3}: 75 \% \mathrm{TiO}_{2}$} & \multicolumn{3}{|c|}{$50 \% \mathrm{Al}_{2} \mathrm{O}_{3}: 50 \% \mathrm{TiO}_{2}$} & \multicolumn{3}{c|}{$75 \% \mathrm{Al}_{2} \mathrm{O}_{3}: 25 \% \mathrm{TiO}_{2}$} \\
\cline { 2 - 12 }$y$ & 1 day & 8 days & 15 days & 1 day & 8 days & 15 days & 1 day & 8 days & 15 days \\
\hline 0,1 & 1,318 & 0,631 & 0,098 & 0,985 & 0,545 & 0,090 & 2,378 & 0,676 & 0,166 \\
\hline 0,3 & 3,528 & 0,362 & 0,147 & 3,493 & 3,125 & 0,248 & 2,892 & 2,430 & 0,324 \\
\hline 0,5 & 3,729 & 3,565 & 0,382 & 3,662 & 3,623 & 0,383 & 3,507 & 3,471 & 0,539 \\
\hline 0,7 & 3,798 & 3,803 & 0,660 & 3,567 & 3,535 & 1,665 & 3,698 & 3,533 & 1,821 \\
\hline
\end{tabular}

Nanofluid From table 1, it can be seen that the absorbance of all hybrid nanofluids decreases with increasing storage time, this indicates a decreased nanofluid hybrid homogenus. And with increasing nanofluid hybrid absorbance volume fraction increases.

Based on the results of absorbance measurements, in the same volume fraction, most of the nanofluid hybrids containing $75 \%$ of $\mathrm{Al}_{2} \mathrm{O}_{3}$ particles have a higher absorbance value. This shows that nanofluid containing more $\mathrm{Al}_{2} \mathrm{O}_{3}$ particles has better stability. The visual agglomeration observation also showed that the same nanofluid hybrid volume fraction containing more $\mathrm{Al}_{2} \mathrm{O}_{3}$ particles had better stability and there was a single nanofluid, $\mathrm{TiO}_{2}$ nanofluid was agglomerated faster than $\mathrm{Al}_{2} \mathrm{O}_{3}$ nanofluid.

Nanofluid hybrid agglomeration which contains more $\mathrm{Al}_{2} \mathrm{O}_{3}$ particles is slower because the browning effect lasts longer in particles and $\mathrm{Al}_{2} \mathrm{O}_{3}$ has a smaller density than $\mathrm{TiO}_{2}$. The slower agglomeration time occurs in the higher volume fraction because in the higher fraction there is a greater frictional force between the nanoparticles so that the nanoparticles will float in the basic fluid which causes the formation of sediment for a long time. This is in accordance with what is stated Geankoplis, [23] that the smaller the density will cause the buoyant force to increase and the greater the concentration of the frictional force experienced by the larger particles.

\subsection{Wettability Hybrid Nanofluid}

Figure 6 is the results of contact angle measurements of hybrid nanofluids and in this study also measured the contact angle of distilled water used as a base fluid and obtained the contact angle value of $107.4^{\circ}$. Based on Figure 6 , it can be seen that the higher the volume fraction of the nanoparticles in the hybrid nanofluid, the smaller the contact angle, this indicates that an increase in volume fraction provides good wettability. All nanofluid hybrids have a smaller contact angle than the contact angle of the distilled water, indicating that the addition of nanoparticles to the base fluid can increase wettability. At a volume fraction of $0.1 \%$ and $0.3 \%$, hybrid nanofluid is hydrophobic (contact angle of more than $90^{\circ}$ ). The hybrid nanofluid volume fraction of $0.7 \%$ with a composition of $75 \% \mathrm{Al}_{2} \mathrm{O}_{3}: 25 \% \mathrm{TiO}_{2}$ has the smallest contact angle of $73.10^{\circ}$. In the same volume fraction, a nanofluid hybrid containing more $\mathrm{Al}_{2} \mathrm{O}_{3}$ particles has a smaller contact angle.

The results of this study are in accordance with research conducted by Chinnam, et.al[24], they examined the contact angle of nanofluid $\mathrm{Al}_{2} \mathrm{O}_{3}, \mathrm{SiO}_{2}$, and $\mathrm{ZnO}$ with variations in volume fraction and using different nanoparticle sizes. Increasing the volume fraction causes the contact angle between the nanofluid and the glass surface to decrease, as well as the $\mathrm{Al}_{2} \mathrm{O}_{3}$ and $\mathrm{SiO}_{2}$ nanofluid with larger particle sizes having smaller contact angles in the same volume fraction. 
Similar results were also obtained in the study Chaudhuri et.al, [25] where the contact angle between $\mathrm{TiO}_{2}$ nanofluidic and PTFE (Teflon) surfaces decreased with an increase in volume fraction.
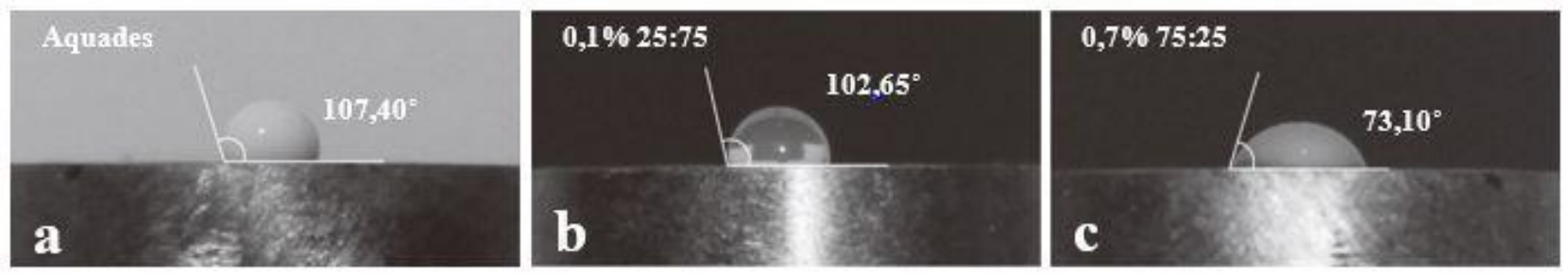

Fig. 6. Angular contact with the wick (a) Aquades powder sintered surface, (b) volume nanofluid fraction volume $0.1 \% 25 \% \mathrm{Al}_{2} \mathrm{O}_{3}$ : $75 \% \mathrm{TiO}_{2}$, (c) hybrid nanofluid fraction volume $0.7 \% 75 \% \mathrm{Al}_{2} \mathrm{O}_{3}: 25 \% \mathrm{TiO}_{2}$.

The contact angle depends on three parameters, namely surface tension, adhesion stress and surface roughness factor Kim et al., [26]. Bhuiyan et al., [27] states that nanofluid surface tension increases with increasing nanoparticle concentration. Tanvir \& Qiao, [28] also states that nanofluid surface tension increases linearly with increasing particle concentration and size. If the surface tension increases, the contact area between the nanofluid and the surface gets larger and the contact angle between the nanofluid is smaller.

The contact angle is affected by the forces that occur in the nanofluid with the surface, including the attraction between the particles, the tensile force between the particles and the solid molecules on the surface. The average size of the nanoparticles is $20 \mathrm{~nm}$ when compared to the much higher water molecules, with a larger size and mass that will cause a downward force when the nanofluid touches the surface. Thus the contact angle will decrease and the wetted area gets bigger. The more nanoparticles in the nanofluid, the stronger the effect occurs. When the volume fraction increases, more particles are found in the nanofluid, reducing the contact angle of the surface. Smaller contact angles in nanofluidic hybrids containing more $\mathrm{Al}_{2} \mathrm{O}_{3}$ particles occur due to the attractive tensile force of $\mathrm{Al}_{2} \mathrm{O}_{3}$ particles with a larger surface than $\mathrm{TiO}_{2}$ particles.

\section{Conclusion}

From the research, it was found that the characters of $\mathrm{Al}_{2} \mathrm{O}_{3}-\mathrm{TiO}_{2}$-water hybrid nanofluid thermal conductivity has a greater value than the conductivity of the water base fluid. The ratio that produces the highest thermal conductivity value is at a ratio of $75 \% \mathrm{Al}_{2} \mathrm{O}_{3}: 25 \% \mathrm{TiO}_{2}$ at a volume fraction of $0.7 \%$ which is $32.50 \%$. The best composition of nanoparticles in increasing hybrid nanofluid thermal conductivity which is significant at $0.7 \%$ volume fraction with an increase in composition 6 times can increase thermal conductivity by $20 \%$ and $32.5 \%$ to water. This proves that there is a significant increase in water (destilated water) at a low volume fraction of $0.7 \%$. Visually, the higher the volume fraction of the nanoparticles in the agglomeration nanofluid, the longer. Hybrid nanofluid absorbance decreases with increasing storage time. Nanofluid hybrid wettability is better with increasing volume fraction, hybrid nanofluid with a volume fraction of $0.1 \%$ and $0.3 \%$ is hydrophobic while the others are hydrophilic.
Hybrid nanofluid is agglomerated longer than $\mathrm{TiO}_{2}$ nanofluid but faster than $\mathrm{Al}_{2} \mathrm{O}_{3}$ nanofluid, higher $\mathrm{TiO}_{2}$ nanoparticle density causes faster agglomeration in $\mathrm{TiO}_{2}$ nanofluid and hybrid nanofluid containing $75 \% \mathrm{TiO}_{2}$ nanoparticles. In the same hybrid volume fraction of nanofluid with a composition of $75 \% \mathrm{Al}_{2} \mathrm{O}_{3}: 25 \% \mathrm{TiO}_{2}$ undergoes longer agglomeration and the absorbance is higher. In the same volume fraction, hybrid nanofluid with $\mathrm{Al}_{2} \mathrm{O}_{3}$ nanoparticles has better wettability than nanofluid hybrids which contain more $\mathrm{TiO}_{2}$ nanoparticles.

Equations Thank you to the Ministry of Technology and Higher Education and the Udayana Institute for Research and Community Service for financial support through the 2018 Higher Education Primary Research Grant (PDUPT) scheme with Contract Number 171.77 / UN14.4.A / PL / 2018.

\section{References}

1. Suresh, S., et al. "Synthesis of $\mathrm{Al}_{2} \mathrm{O}_{3}-\mathrm{Cu} /$ water hybrid nanofluids using two-step method and its thermo physical properties." Colloids and Surfaces A: Physicochemical and Engineering Aspects 388(1-3): 41-48 (2011).

2. Wang, X.-Q. and A. S. Mujumdar. "Heat transfer characteristics of nanofluids: a review." International journal of thermal sciences 46(1): 119 (2007).

3. Minea, A. A. "Hybrid nanofluids based on $\mathrm{Al}_{2} \mathrm{O}_{3}$, $\mathrm{TiO}_{2}$, and $\mathrm{SiO}_{2}$ : numerical evaluation of different approaches." International Journal of Heat and Mass Transfer 104: 852-860 (2017).

4. Selim Ahlatli, Thierry Mare, Patrice Estelle, Nimet Doner. "Thermal Performance Of Carbon Nanotube Nanofluids In Solar Microchannel Collectors: An Experimental Study". International Journal of Technology 2: 219-226 (2016)

5. Sarkar, J., et al. "A review on hybrid nanofluids: recent research, development, and applications." Renewable and Sustainable Energy Reviews 43: 164-177 (2015).

6. Hatwar, A. S. and V. Kriplani. "A review on heat transfer enhancement with nanofluid." Int. J. Adv. Res. Sci. Eng 3(3): 175-183 (2014).

7. Nandy Putra, Wayan Nata Septiadi, Gerry Julian, Ary Maulana, Ridho Irwansyah. "An Experimental 
Study On Thermal Performance Of Nano Fluids In Microchannel Heat Exchanger". International Journal of Technology 2: 167-177 (2013).

8. Nandy PutraWilfried Roetzel, Sarit K. Das. Natural convection of nano-fluids. Heat and Mass Transfer. pp 775-784 (2003)

9. Kouloulias, K., et al. "Sedimentation in nanofluids during a natural convection experiment." International Journal of Heat and Mass Transfer 101: 1193-1203 (2016).

10. Khaleduzzaman, $\mathrm{S}$., et al. "Stability of $\mathrm{Al}_{2} \mathrm{O}_{3}$-water Nanofluid for Electronics Cooling System." Procedia engineering 105: 406-411 (2015).

11. Babu, J. R., et al. "State-of-art review on hybrid nanofluids." Renewable and Sustainable Energy Reviews 77: 551-565 (2017).

12. Ilyas, S. U., et al. "Stability and agglomeration of alumina nanoparticles in ethanol-water mixtures." Procedia Engineering 148: 290-297 (2016).

13. Sidik, N. A. C., et al. "Recent progress on hybrid nanofluids in heat transfer applications: a comprehensive review." International Communications in Heat and Mass Transfer 78: 6879 (2016).

14. Nandy Putra, Erwin Prawiro, Muhammad Amin. "Thermal Properties Of Beeswax/Cuo Nano PhaseChange Material Used For Thermal Energy Storage". International Journal of Technology 2: 244-253 (2016).

15. Devendiran, D. K. and V. A. Amirtham. "A review on preparation, characterization, properties and applications of nanofluids." Renewable and Sustainable Energy Reviews 60: 21-40 (2016).

16. Esfe, M. H., et al. "Study on thermal conductivity of water-based nanofluids with hybrid suspensions of CNTs $/ \mathrm{Al}_{2} \mathrm{O}_{3}$ nanoparticles." Journal of Thermal Analysis and Calorimetry 124(1): 455-460 (2016).

17. Akilu, S., et al. "Experimental measurements of thermal conductivity and viscosity of ethylene glycol-based hybrid nanofluid with $\mathrm{TiO}_{2}-\mathrm{CuO} / \mathrm{C}$ inclusions." Journal of Molecular Liquids 246: 396405 (2017).

18. Charab, A. A., et al. "Thermal conductivity of $\mathrm{Al}_{2} \mathrm{O}_{3}+\mathrm{TiO}_{2}$ /water nanofluid: Model development and experimental validation." Applied Thermal Engineering 119: 42-51(2017).

19. Leong, K., et al. "Synthesis and thermal conductivity characteristic of hybrid nanofluids-a review." Renewable and Sustainable Energy Reviews 75: 868-878 (2017).

20. Azwadi, C. N., et al. "Preparation methods and thermal performance of hybrid nanofluids." J. Adv. Rev. Sci. Res. 24(1): 13-23 (2016).

21. $\mathrm{Yu}, \mathrm{W}$. and $\mathrm{H}$. Xie "A review on nanofluids: preparation, stability mechanisms, and applications." Journal of nanomaterials 2012: 1 (2012).
22. Esfe, M. H., et al. "Thermal conductivity of $\mathrm{Cu} / \mathrm{TiO}_{2}$-water/EG hybrid nanofluid: Experimental data and modeling using artificial neural network and correlation." International Communications in Heat and Mass Transfer 66: 100-104 (2015).

23. Geankoplis, C. J. Transport processes and separation process principles:(includes unit operations), Prentice Hall Professional Technical Reference. (2003).

24. Chinnam, J., et al. "Measurements of the contact angle of nanofluids and development of a new correlation. "International Communications in Heat and Mass Transfer 62: 1-12 (2015).

25. Chaudhuri, R. G. and S. Paria. "The wettability of PTFE and glass surfaces by nanofluids." Journal of colloid and interface science 434: 141-151 (2014).

26. Kim, S., et al. "Effects of nanoparticle deposition on surface wettability influencing boiling heat transfer in nanofluids." Applied Physics Letters 89(15): 153107 (2006).

27. Bhuiyan, M., et al. "Effect of nanoparticles concentration and their sizes on surface tension of nanofluids." Procedia Engineering 105: 431-437 (2015).

28. Tanvir, S. and L. Qiao "Surface tension of nanofluid-type fuels containing suspended nanomaterials." Nanoscale research letters 7(1): 226 (2012) 